\title{
REPRESENTAÇÕES PUBLICITÁRIAS: PERSUASÃO, NATURALIZAÇÃO E DISPUTA PELO HEGEMÔNICO ENTRE A ECONOMIA E A CULTURA
}

\author{
Advertising representations: persuasion, naturalization and dispute for the \\ hegemonic between economy and culture
Representación publicitaria: persuasión, naturalización y disputa por lo hegemonico entre la economía y la cultura

Nathália dos Santos Silva

Mestre em Comunicação e Informação pela UFRGS. nathalia.ssilva@yahoo.com.br

\begin{abstract}
Elisa Reinhardt Piedras
Profa. Dra. do Departamento de Comunicação e do Programa de Pós-Graduação em

Comunicação da UFRGS. elisapiedras@gmail.com
\end{abstract}

\section{Resumo}

Este artigo tem o objetivo de apresentar as contribuições da questão das representações para a pesquisa em publicidade no contexto brasileiro contemporâneo. Na discussão teórica realizada a partir de uma pesquisa bibliográfica, retomamos as perspectivas das representações desenvolvidas por Moscovici, Goffman e Hall, para articulá-las aos estudos da publicidade. Ilustramos o debate sobre possibilidades de operacionalização analítica das representações publicitárias destacando as contribuições de pesquisadores como Rocha, Gastaldo e Iribure. Entre os traços comuns das pesquisas que tecem o diálogo das representações com a publicidade, identificamos a discussão sobre as dinâmicas de manutenção ou transformação de representações hegemônicas e sua vinculação às diferentes práticas, contextos e grupos sociais que o processo comunicativo publicitário aproxima.

Palavras-chave: Publicidade e propaganda. Representações. Perspectivas teóricas.

\begin{abstract}
This paper aims to present the contributions of the discussion on representations to advertising's research in contemporary brazilian context. As the theoretical scope, defined from a bibliographic research, we resume the concepts on representations in the perspective of Moscovici, Goffman and Hall, articulated with studies on advertising. We illustrate the debate about possibilities of analytical operationalization of advertising representations highlighting the contributions of researchers such as Rocha, Gastaldo and Iribure. Among the common features of the researches, we identify the discussion about the dynamics of maintenance or transformation of hegemonic representations and its articulation to different practices, contexts and social groups that the communicative process of advertising approaches.
\end{abstract}


Key words: Advertising. Representations. Theoretical perspectives.

\section{Resumen}

Este artículo tiene como objetivo presentar las contribuciones de la cuestión de la representación a la investigación de la publicidad en el contexto contemporáneo de Brasil. En la discusión teórica realizada a partir de una búsqueda en la literatura, reanudamos las perspectivas de las representaciones elaboradas por Moscovici, Goffman y Hall, para articularlas a los estudios de publicidad. Se ilustra el debate sobre las posibilidades de operacionalización de análisis de las representaciones publicitarias destacando las contribuciones de los investigadores como Rocha, Gastaldo y Iribure. Entre los rasgos comunes de las investigaciones, identificamos la discusión sobre las dinámicas de mantenimiento o transformación de las representaciones hegemónicas y su relación con las diferentes prácticas, contextos y grupos sociales que se acerca el proceso de comunicación publicitaria.

Palabras clave: Publicidad y propaganda. Representaciones. Perspectivas teóricas.

\section{INTRODUÇÃO}

A discussão sobre as representações tem uma longa trajetória, cujas bases remontam à sociologia durkheimiana do final do século XIX. Ao abordar o constructo social e a sua manutenção, a sociologia do conhecimento deu seus primeiros passos através da noção de representações coletivas. A ideia remete a um conjunto de conceitos socialmente construídos, partilhados e ritualizados que orientam ativamente as práticas e as formas de organização sociais. Tal abordagem, articulada ao estudo dos processos interpretativos, passou a ser retomada em diferentes campos do conhecimento (como a história, a psicologia, os estudos da linguagem) e se consolidou como tema de relevância na investigação de caráter socioantropológico.

O campo da comunicação, por sua vez, também incorporou a questão das representações, tema que prosperou nas pesquisas de uma variedade de gêneros midiáticos e instâncias dos processos comunicativos. As investigações, frequentemente situadas no debate da construção da realidade social, abordam as representações através das disputas envolvidas na consolidação de estereótipos ou estigmas, da representatividade de temas ou grupos sociais nas narrativas midiáticas, ou do próprio processo de significação.

Especificamente no cenário da pesquisa brasileira no campo da comunicação que tem como objeto a publicidade, é crescente o interesse na investigação das representações. Levantamentos como o de Jacks (2001), sobre a pesquisa dos anos 1990, têm destacado o 
privilégio dado ao texto ou produto midiático nas abordagens desse objeto, e a perspectiva das representações encontra um terreno fértil na análise de anúncios publicitários.

Recentemente, no período entre 2010 e 2015, mais de um quinto da produção da área esteve voltada para esse tema: representações e publicidade. Através de levantamento realizado nos repositórios digitais que disponibilizam teses e dissertações de Programas de Pós-Graduação em Comunicação, do total de 236 estudos sobre publicidade e propaganda (identificados pelas palavras-chave "publicidade", "propaganda" e "anúncio"), 44 estavam pautados pela questão das representações. Tal panorama indica a consolidação de um viés que aborda a publicidade em relação à cultura, atento às disputas de poder e de significado que a constroem.

Essas pesquisas têm como objeto de estudo tanto o texto publicitário quanto a relação dos sujeitos com as representações que circulam a partir dele. A noção de representações é bastante fundamentada pelas ideias de Hall, mas também de autores como Moscovici, Durkheim, Geertz e Goffman. No âmbito metodológico, vigora a abordagem qualitativa e os procedimentos recorrem a uma diversidade de procedimentos: pesquisa bibliográfica, análise documental, análise de conteúdo, análise de discurso, análise semiótica e semiológica, hermenêutica de profundidade, "etnografia do anúncio", narratologia. As análises dão continuidade para as discussões relativas aos sujeitos, seja no estudo das representações publicitárias sobre gênero e sexualidades, sobre identidades étnicas e nacionais, sobre identidades geracionais (a criança, os jovens, os idosos) ou sobre o corpo; ou têm explorado as representações publicitárias sobre grandes temas, como o consumo, a felicidade, a cidade e a cidadania, o sexo, o futebol, o meio ambiente (sustentabilidade), o capitalismo, o comunismo; ou, ainda, têm se preocupado com representações sobre produtos, explorando o tema das tecnologias, dos alimentos, dos automóveis ou da moda, para dar alguns exemplos.

Diante da ênfase dada às representações pela produção científica brasileira sobre publicidade, consideramos relevante resgatar fundamentos teóricos e destacar o quanto tem sido fecunda essa articulação. Nosso objetivo neste artigo é apresentar as contribuições da questão das representações para a pesquisa em publicidade no contexto brasileiro contemporâneo. Tal discussão teórica é desenvolvida através de uma pesquisa bibliográfica (STUMPF, 2008), na qual retomamos as perspectivas de Moscovici (1978[1961]), Goffman (1979) e Hall (2016[1997]) sobre as representações para articulá-las aos estudos da publicidade. Em seguida, ilustramos o debate com algumas possibilidades de operacionalização analítica das representações publicitárias, destacando as contribuições de 
três estudos situados em diferentes vieses de análise. Com esse trabalho, esperamos identificar aspectos comuns das pesquisas que tecem o diálogo das representações com a publicidade, bem como destacar suas principais contribuições para o campo da comunicação no Brasil.

A seguir, apresentamos algumas notas teóricas sobre representações e publicidade. Antes disso, cabe situar o leitor quanto ao fato de que a discussão sobre representações se desenvolveu historicamente com ênfases distintas, e é essa heterogeneidade que visamos contemplar, ainda que brevemente. Isso justifica a opção de resgatar, além da noção durkheimiana, a especificidade das perspectivas de Moscovici (1978), Goffman (1979) e Hall (2016). Afinal, enquanto Goffman aborda a "representação" como dramatização das relações cotidianas e sua reafirmação nas imagens publicitárias, Moscovici trata das "representações sociais" enquanto conjunto de ideias, saberes de senso comum vinculados a grupos e práticas, e Hall associa as representações a processos de significação numa cultura.

Tendo essas visões como base teórica sobre as representações, discutimos brevemente a publicidade desde um olhar cultural, tentando mais uma vez contemplar diferentes abordagens. Para isso, destacamos o pensamento de Williams (1995[1961]) por deslocar, de modo inaugural, a compreensão da publicidade limitada à atuação na esfera econômica para, então, tratá-la como produto cultural. A partir daí, abordagens da comunicação persuasiva ${ }^{1}$ nas dinâmicas sociais desenvolvem-se no âmbito de sua linguagem, de seu discurso, das práticas de produção, de recepção, ou mesmo de seu processo comunicativo como um todo. Contemplando o viés sociodiscursivo, resgatamos o estudo de Colón Zayas (2001) sobre as "matrizes discursivas da publicidade" e seu papel na manutenção da hegemonia do projeto cultural capitalista. Já para dar conta de uma abordagem processual e sociocultural da publicidade, retomamos algumas contribuições do mapa conceitual proposto por Piedras (2009). Articulando essas abordagens às teorias sobre representações, buscamos refletir sobre a especificidade das representações postas em circulação pelo processo comunicativo publicitário.

Após essa fundamentação teórica, reunimos alguns traços do cenário da pesquisa brasileira sobre representações publicitárias em seus distintos vieses de análise a partir das contribuições de Rocha (1990), Gastaldo (2002) e Iribure (2008). Dentre toda a produção

\footnotetext{
${ }^{1}$ Entendemos que a publicidade é persuasiva (e não manipuladora) no sentido de sedução apresentado por Baudrillard (1991), como um jogo de cumplicidade. É através dela que os publicitários se deslocam de seu lugar de produção para se aproximar do consumidor. A comunicação persuasiva envolve tanto a publicidade quanto a propaganda, que, segundo Gomes (1998), diferenciam-se: a propaganda remete à divulgação de ideias e de pessoas e a publicidade é caracterizada pela divulgação de produtos e serviços, vinculada ao mercado e à cultura de consumo.
} 
científica brasileira dedicada ao estudo das representações publicitárias, consideramos interessante ilustrar o debate a partir desses três pesquisadores devido a sua trajetória de investigação e qualidade de suas contribuições. Além disso, tais estudos envolvem propostas de operacionalização do binômio publicidade e representações que ecoam aquela heterogeneidade que tentamos contemplar ao abordar esta última questão.

Rocha (1990) assumiu a antropologia simbólica na análise das "lógicas" que atravessam a criação e o consumo dos anúncios, suas narrativas e as atribuições de significado, operacionalizando a concepção das representações como sistemas classificatórios que fixam a publicidade junto ao social, em diálogo com a noção de "representações coletivas". Já Gastaldo (2002) analisou a forma como um determinado tema apareceu nas imagens publicitárias, combinando a estratégia de operacionalização goffmaniana ao que chamou "descrição densa" do anúncio. Isso foi articulado a questões relativas às relações de poder vinculadas às representações, tanto na perspectiva de Goffman quanto de Hall. Por sua vez, Iribure (2008) propôs uma abordagem diacrônica da publicidade. Operacionalizou os conceitos da Teoria das Representações Sociais de Moscovici na análise de três décadas de anúncios televisivos, buscando enfatizar possíveis transformações nas representações hegemônicas na publicidade.

\section{NOTAS TEÓRICAS SOBRE REPRESENTAÇÕES E PUBLICIDADE}

Como adiantamos, a base da discussão sobre representações está na noção durkheimiana de representações coletivas, que remete a um conjunto de crenças e sentimentos comuns, "pré-noções" ou regras de conduta pressionando o ser individual. Junto de Mauss, Durkheim discutiu as representações como formas simbólicas de classificação que se originam no mundo social e estão em relação de correspondência com suas formas de organização. À exemplo dos sistemas mágico-totêmicos, as categorias lógicas de classificação do mundo são categorias sociais (DURKHEIM; MAUSS, 2008[1902]).

Buscando explorar o que ocorre entre o coletivo e o individual, essa discussão foi apropriada no campo da psicologia social na segunda metade do século XX por Moscovici (1978[1961]). Seus estudos aprofundaram aspectos da noção durkheimiana das representações, como sua natureza convencional e prescritiva enquanto categorias do pensamento. Ao elaborar a Teoria das Representações Sociais, Moscovici viabilizou uma abordagem das representações como fenômeno. Mais do que um conjunto estável de 
significados, um produto e processo social, tal como estruturas dinâmicas, mediadoras e comunicativas (MOSCOVICI, 1978[1961]). A Teoria forneceu, assim, um quadro conceitual relevante para tratar dos processos de emergência, formação e circulação das representações.

Dessa perspectiva, destacamos a ênfase dada ao papel da comunicação, implicada nas “[...] trocas e interações que concorrem para a criação de um universo consensual”, já que engaja "processos de interação social, influência, consenso ou dissenso e polêmica" (JODELET, 2001, p. 30). Além de compor as condições de emergência de um esquema de representação, a comunicação também incide sobre sua formação através dos mecanismos de objetivação e ancoragem. A objetivação vincula a ideia ainda abstrata a um núcleo figurativo, forja sua "qualidade icônica" e naturaliza essa vinculação, objetivando-a (MOSCOVICI, 2003, p. 70-71). Para isso, cada sociedade seleciona os conceitos "[...] aos quais ela concede poderes figurativos, de acordo com suas crenças e com o estoque preexistente de imagens [...]" (MOSCOVICI, 2003, p. 72). Há, nesse mecanismo, um processo de "construção seletiva" e "esquematização estruturante do núcleo figurativo" que manifesta "o efeito da comunicação e das pressões, ligadas à pertença social dos sujeitos, sobre a escolha e a organização dos elementos constitutivos da representação" (JODELET, 2001, p. 38). Esse esquema passa a ser naturalizado, dando à representação "valor de realidades concretas, diretamente legíveis e utilizáveis na ação sobre o mundo e os outros" (JODELET, 2001, p. 39). Já o mecanismo da ancoragem assegura a incorporação das representações ao social à medida que "[...] enraíza a representação e seu objeto numa rede de significações que permite situá-los em relação aos valores sociais e dar-lhes coerência” (JODELET, 2001, p. 39), chamando a representação a ocupar um espaço em relação ao já conhecido ${ }^{2}$, como uma continuação da objetivação. Incidindo sobre esses processos, a comunicação, "sob seus aspectos interindividuais, institucionais e midiáticos, aparece como condição de possibilidade e de determinação das representações [...]” (JODELET, 2001, p. 30).

Nessa perspectiva, as representações são uma estrutura mediadora que organiza a si mesma através da ação comunicativa ${ }^{3}$ que liga ou separa os sujeitos e o objeto-mundo, situando-os "em uma relação concreta, amarrada ao contexto social, cultural e histórico em que elas [as representações] se encontram e ativamente (re)produzem" (JOVCHELOVITCH, 2011, p. 74). Na medida quem são partilhadas, a própria inserção social dos indivíduos é

\footnotetext{
${ }^{2}$ Cabe acrescentar a contribuição da vertente estruturalista da Teoria, que enfatiza a hipótese de que uma representação é estruturada por um núcleo central, estável e homogêneo, e pelo seu sistema periférico, mais flexível. Diante de uma realidade que questiona e contradiz a representação, o esquema periférico absorve tais desacordos e a estabiliza (ABRIC, 2001).

3 “Ação comunicativa”, no sentido de Habermas (apud JOVCHELOVITCH, 2011, p. 71).
} 
operada pelas representações. A partilha implica na relação ideológica que os indivíduos mantêm com o social, sua pertença, sua condição. Dessa forma que a partilha das representações contribui na "manutenção da identidade social e do equilíbrio sócio cognitivo a ela ligados" (JODELET, 2001, p. 35).

Por sua vez, na sociologia de Goffman (1979), a preocupação com a manutenção ou naturalização emerge na noção de ritualização da representação. Aqui, a ideia de representação tem paralelo no fazer teatral, remete à representação de papéis nos espaços de interação cotidiana. Essa abordagem permite problematizar a forma como a conduta é orientada por uma determinada leitura da situação social em questão, discutindo a coerção que a naturalização e a legitimação de um determinado código de leitura dos comportamentos exerce ao "indicar" o que está acontecendo e quais ações são esperadas (GOFFMAN, 1979).

Esse tipo específico de representação é chamado de display, um código de "comportamento expressivo" que produz indicativos, sinais ou evidências que informam sobre a identidade das pessoas e as situações de interação. Os displays são mais efetivos em "informar" quanto mais ritualizados estiverem, quanto mais estabelecido estiver o "código", o que depende da sua repetição cotidiana, da sua ritualização. A noção de ritualização está, portanto, vinculada à consolidação desses códigos em função de sua emergência em um amplo conjunto de relações sociais (GOFFMAN, 1979).

Ganha ênfase, aqui, a questão do poder. É justamente essa repetição que permite aos comportamentos serem expressivos, significativos, parecerem "evidentes", "naturais"4, compondo a própria conjuntura das situações sociais em que são performados. Na ritualização que consolida a significação dos "comportamentos expressivos", os indivíduos “[...] estão aprendendo a ser objetos que têm uma característica, que expressam essa característica e para os quais a expressão dessa característica é apenas natural” (GOFFMAN, 1979, p. 7, tradução nossa). Para o autor, essas representações não apenas afirmam uma hierarquia social, mas a constituem: "nós somos socializados para confirmar nossas próprias hipóteses sobre nossas naturezas" (p. 7).

Se a representação dos papéis e situações sociais é ritualizada por si mesma na vida cotidiana, a representação midiática dessas situações resulta numa "hiperritualização". É o caso das imagens publicitárias, na perspectiva de Goffman (1979). Reproduzidos nos

\footnotetext{
${ }^{4}$ Por exemplo, fundamentando os "displays de gênero" (objeto específico do estudo de Goffman), há uma crença de que parecemos homens ou mulheres porque nossa "natureza" se "expressa espontaneamente", há uma "doutrina da expressão natural” (“doctrine of natural expression”) através da qual acredita-se que os objetos expressam uma natureza essencial independentemente da forma (e dos interesses) com que olhamos para eles.
} 
anúncios, os displays são descolados das situações em que operam como códigos de comportamentos expressivos e são dramatizados de forma proposital para serem ainda mais significativos e indicativos da cena narrada. Ao fazer isso, a publicidade se engaja em mostrar "categorias de pessoas" que possam ser reconhecidas como performadas na vida real $^{5}$. Para Goffman (1979), emerge daí a naturalização de uma determinada relação de poder, à exemplo dos displays de gênero, em que o comportamento feminino está sempre em relação de submissão e inferioridade diante do masculino.

A representação também foi discutida na perspectiva dos Estudos Culturais, voltada para as relações entre comunicação e cultura. Na obra de Hall (2016) ${ }^{6}$, duas ênfases são relevantes: a representação midiática em diálogo com Goffman e a representação enquanto processo de significação, próxima das abordagens linguísticas. A primeira ênfase se insere nos estudos voltados para a representação de determinados grupos sociais nos produtos midiáticos, discussão ilustrada no debate sobre "estereótipos raciais", à exemplo da chamada “encenação da diferença racial" (HALL, 2016, p. 175). Por outro lado, partindo das teorias da linguagem e da semiótica, Hall assume uma concepção de representação associada às práticas de significação, atravessadas por relações de poder enquanto elemento chave da cultura.

Essa perspectiva permite que o autor aborde a representação nos processos de identificação dos sujeitos (identidades) e de regulação da cultura. Afinal, nesse viés, as representações explicam a forma como participantes de uma cultura dão significado às coisas no mundo: “[...] as palavras que usamos para nos referir a elas, as histórias que narramos a seu respeito, as imagens que delas criamos, as emoções que associamos a elas, as maneiras como as classificamos e conceituamos, os valores que nelas embutimos" (HALL, 2016, p. 21).

Tais convenções indicam a partilha de representações entre os sujeitos, aparelhados de um "know-how cultural" que os "equipa com uma habilidade cultural" e permite que atuem como "sujeitos culturalmente competentes" (HALL, 2016, p. 43). Essa partilha, não sendo óbvia ou natural, remete ao "sentido preferencial"” de alguma mensagem (HALL, 2003). Trata-se de um consenso quanto à ordem hegemônica: "significados preferenciais dependem do 'senso comum' [...] e refletem a ordem cultural dominante [...] num nível institucional,

\footnotetext{
${ }^{5}$ Em "Gender Advertisements" (GOFFMAN, 1979), o autor analisou apenas as fotografias dos anúncios.

6 A obra "Representation: Cultural Representations and Signifying Practices" (1997) recebeu este ano uma edição na língua portuguesa pelas editoras PUC-Rio e Apicuri (2016), com tradução de Daniel Miranda e William Oliveira, demonstrando que a discussão se mantem relevante.

7 O trabalho "Codificação/ Decodificação" (HALL, 2003), publicado na década de 1980, destacou os processos de codificação de uma mensagem (produção) e sua decodificação (recepção), para argumentar que o sentido é sempre negociado e circula a partir da atividade do emissor tanto quanto da audiência.
} 
político e ideológico", como observa James Procter (2004, p. 68, tradução nossa) sobre o trabalho de Hall.

As três hipóteses sobre as posições do receptor diante dos sentidos ofertados (HALL, 2003) podem ser interpretadas como diferentes formas de compartilhar das representações, negociando a relação com elas. Afinal, a partilha supõe adesão e participação e está relacionada com a forma com que o indivíduo se insere nas estruturas sociais, como vimos também com Jodelet (2001). Assim, sujeitos inseridos em uma mesma cultura não partilharão exatamente das mesmas representações de uma forma consensual, mas irão confrontar-se com elas ou investir nelas. Nesse sentido, o "processo de identificação" (HALL, 2014), enquanto modo de partilha de representações, refere-se à afirmação de um vínculo social (JODELET, 2001).

Dessa forma, as convenções sociais, os esquemas partilhados ou o senso comum produzem o efeito de naturalidade e universalidade ("as coisas tais como são") que contribui para a manutenção da hegemonia (PROCTER, 2004). Afinal, os "significados culturais" "[...] organizam e regulam práticas sociais, influenciam nossa conduta e consequentemente geram efeitos reais e práticos" (HALL, 2016, p. 20). Assim, Hall compreende os regimes de representação como um lugar de disputa e negociação da hegemonia na cultura.

Os regimes de representação hegemônicos têm lugar privilegiado na comunicação publicitária, e esse debate contribui para a compreensão de seu relevante papel em processos socioculturais mais amplos, como o consumo, as identidades ou as relações de poder. Afinal, se os processos de representação (significação) numa cultura constituem um campo de disputa, negociação, identificação e regulação (HALL, 2016), o sistema de representação da publicidade expressa os códigos mais hegemônicos, hiperritualizados (GOFFMAN, 1979), dominantes, harmonizados com o conjunto de práticas e relações sociais que caracterizam a sociedade capitalista.

Desde Williams, há a compreensão da publicidade como um sistema que ultrapassa "a fronteira da venda de produtos e serviços" e se organiza a partir de "um padrão cultural no qual os objetos não são suficientes, mas precisam ser validados, mesmo que na fantasia, pela associação com significados sociais e pessoais" (WILLIAMS, 1995 [1961], p. 335, tradução nossa). Nessa concepção, a publicidade é marcada por um aspecto um tanto falacioso, que associa valores a produtos e transborda seu lugar no contexto comercial para as dinâmicas mais gerais do sistema social e cultural da sociedade moderna do século XX. 
Para Colón Zayas (2001), a publicidade é um “[...] gênero discursivo capaz de propor suas próprias formas de ver e conceitualizar a realidade", reordenando-a segundo o projeto cultural capitalista (COLÓN ZAYAS, 2001, p. 80, tradução nossa). Segundo ele, a publicidade compôs o "[...] repertório de signos narrativos que se apresentaram a partir do século XVII com o desenvolvimento do capitalismo industrial", e que "[...] correspondem a uma ideologia e constituem uma forma de falar e uma forma de representação específica" (COLÓN ZAYAS, 2001, p. 12-13, tradução nossa). A comunicação persuasiva emerge como um "novo sensório" que, na perspectiva do autor, se converte em um dos eixos principais da subjetividade contemporânea (baseada na propriedade privada, na cultura de mercado, na fragmentação e na descontextualização da realidade cotidiana onde circulam os produtos) (COLÓN ZAYAS, 2001). É, portanto, “[...] dentro deste espaço que a publicidade se constitui como discurso hegemônico da modernidade [...]" (COLÓN ZAYAS, 2001, p. 134, tradução nossa).

Se as representações sempre estão "ligadas a uma condição definida no seio da estrutura social" (JODELET, 2001, p. 32), no caso da publicidade, o estudo das representações não pode ignorar sua articulação com o capitalismo enquanto sistema econômico e projeto cultural (COLÓN ZAYAS, 2001). Assim, abordando a publicidade como discurso, repertório de signos, sensório e mesmo linguagem, o autor a situa na cultura e no campo de disputa pelas representações hegemônicas e dominantes, articuladas à esfera econômica.

Considerando a representação como estrutura mediadora e comunicativa (MOSCOVICI, 2001; JOVCHELOVITCH, 2011), e como lugar de naturalização (GOFFMAN, 1979) ou disputa e negociação da hegemonia na cultura (HALL, 2016), as representações publicitárias também podem ser compreendidas no âmbito do processo comunicativo que as engendra.

Esse processo é marcado pela articulação entre a publicidade e outras esferas do mundo social (tal qual a esfera econômica, como estudado por Colón Zayas) e por uma ““dupla articulação’ promovida pela publicidade entre as práticas de produção e as práticas de recepção" (PIEDRAS, 2009, p. 80). Segundo a autora, a interseção entre essas práticas vai desde o apelo aos repertórios culturais dos receptores nas práticas de criação dos anúncios até a inter-relação entre a competência cultural dos receptores e as ofertas da produção. Assim, “[...] se, em um momento as práticas de recepção oferecem subsídios para determinar a produção dos anúncios, em outro, a estrutura econômica e as práticas de produção 
condicionam a sua recepção" (p. 80). É essa "dupla articulação" que incide, ao nosso ver, sobre a organização e circulação das representações publicitárias, cujos elementos estão implicados também pela sua articulação com o mundo social. Se toda a representação é sempre configurada em relação a uma memória, familiarizada no já conhecido, ancorada em outras representações (MOSCOVICI, 1978 [1961], 2003), também as representações publicitárias são formuladas ancorando-se em outras representações sociais, vinculadas às diferentes práticas, contextos, e grupos sociais que o processo comunicativo publicitário aproxima.

A compreensão da publicidade como sistema fantasioso (WILLIAMS, 1995), imagem "hiperritualizada" (GOFFMAN, 1979), regime de significados vinculado ao capitalismo (COLÓN ZAYAS, 2001) ou processo de comunicação constituído por articulações entre práticas e esferas distintas do mundo social (PIEDRAS, 2009), permite elencar uma variedade de elementos que incidem sobre a organização e circulação das representações publicitárias e explicam sua vinculação com dinâmicas socioculturais mais amplas. Diante desse quadro teórico, a pergunta se volta para sua operacionalização analítica, e, nesse sentido, destacamos contribuições de estudos produzidos sobre o tema no contexto brasileiro.

\section{UM CENÁRIO DA PESQUISA BRASILEIRA SOBRE REPRESENTAÇÕES PUBLICITÁRIAS}

Sendo precursor na abordagem cultural da publicidade no Brasil, Everardo Rocha ${ }^{8}$ (1990) a aborda como operador totêmico, que atua na sociedade capitalista tal como as crenças mágico-totêmicas atuam nas sociedades estudadas por Lévi-Strauss. Como sistema mágico, a publicidade "categoriza e ordena o universo", "hierarquiza e classifica produtos e grupos sociais" (ROCHA, 1990, p. 26), constrói uma ponte entre mundos antagônicos, configurados por lógicas diferentes: o da produção e o do consumo. Apenas nas crenças mágico-totêmicas, pólos de oposição são aproximados de forma não problemática, classificando os opostos como complementares (como humanos e produtos) e os iguais como distintos (diferenciação entre os produtos).

\footnotetext{
${ }^{8}$ Para essa discussão serão consideradas principalmente as contribuições do livro "Magia e Capitalismo: um estudo antropológico da publicidade" que foi fruto de sua dissertação de mestrado (ROCHA, 1990). Além desta obra, livros como "A sociedade do sonho" (1995), "Representações do consumo" (2006) e outras publicações recentes trazem importantes contribuições do autor para a compreensão do tema.
} 
Em aproximação com a antropologia simbólica, a observação de características como a suspensão do tempo cronológico, a fala sobre uma "outra vida", a narrativa de "feitos mágicos" realizados com facilidade a partir de "objetos mágicos" e a supressão da distinção entre Natureza e Cultura, permitiram o paralelo da publicidade com a noção de mito (ROCHA, 1990). Tal como num conjunto de mitos, um conjunto de anúncios apresenta estruturas invariantes: a intervenção do produto atravessa e ordena diferentes narrativas em torno de uma mesma história, mais ampla, daquele "objeto mágico" e dos feitos que realiza. Como um sistema de mitos, os anúncios vão construindo, em conjunto, “[...] uma vida idealizada, de 'momentos felizes' e permanentes, que apenas habitam em eterna sucessão o mundo dos anúncios publicitários" (ROCHA, 1990, p. 144).

Rocha (1990) propõe, ainda, o estudo da publicidade em paralelo com o rito, enfatizando as instâncias da recepção e do consumo. Rearranjados pela publicidade, aspectos da realidade são deslocados, recontextualizados e investidos de novos significados. Tanto o mito quanto o rito são "formas de uma sociedade falar de si mesma" e expressam as maneiras pelas quais "uma sociedade destaca, focaliza, vê, se aproxima, coloca em close-up suas questões, impasses, dúvidas e paradoxos" (ROCHA, 1990, p. 154).

Concebida como um sistema totêmico, um mito ou um rito, o procedimento de análise da publicidade passa pela indagação da forma como as pessoas atribuem significados a certos anúncios (ROCHA, 199). A investigação busca a compreensão das "lógicas" que atravessavam a criação dos anúncios (a partir do contato com agências de publicidade e suas formas de trabalho) e explora as categorias de produção e consumo (observando, nessa articulação, a lógica totêmica). Além disso, a partir da interpretação dos anúncios por informantes, emergem as operações classificatórias (evidenciando o modelo do totemismo como operador de diferenças); e "a forma pela qual a publicidade fixa junto ao corpo social esse sistema de classificação", ou seja, os mecanismos através dos quais "a sociedade pode acreditar no "mundo dentro dos anúncios"”, o lugar de fala da publicidade, o significado da “instituição publicitária” (ROCHA, 1990, p. 33).

Toda essa busca pelas estruturas de significação na pesquisa de Rocha (1990) fundamenta a compreensão das representações publicitárias como um lugar de expressão e tematização de "impasses, dúvidas e paradoxos" de uma sociedade. Em diálogo com a noção de representações coletivas estudada por Durkheim e Mauss, e assumindo a perspectiva antropológica simbólica, a proposta de Rocha (1990) direciona o olhar à publicidade para 
questões mais gerais, que problematizam a maneira como suas narrativas se inserem no cotidiano, tal como um fato da vida social.

Por sua vez, a abordagem de Édison Gastaldo9 (2002) discute as relações entre futebol e cultura brasileira na ocasião da Copa do Mundo de 1998. As representações são compreendidas como parte da própria dinâmica cultural das sociedades, o que viabiliza tratar da participação da publicidade no campo de lutas onde "diferentes articulações de significados atribuídos aos fenômenos competem entre si para permanecer ou tornar-se o significado predominante" (GASTALDO, 2002, p. 70).

Diante de um corpus de análise recortado a partir das alusões ao tema pesquisado (através de elementos visuais, sonoros ou textuais), a descrição dos anúncios busca o "segundo plano de significação", onde "naturalizam-se' relações de poder socialmente construídas" (GASTALDO, 2002, p. 95). Através da apropriação da perspectiva de Goffman, Gastaldo observa recorrências dos padrões de representação do mesmo tema entre os anúncios. A análise, atenta ao contexto dos anúncios, destaca o papel de outros gêneros midiáticos nas representações sobre o tema estudado, por vezes, "saturando" o assunto mais que a própria publicidade, à exemplo do jornalismo.

Com esse olhar sobre o segundo plano de significação dos anúncios, o estudo contribui para a interpretação do potencial ideológico midiático, que “[...] se manifesta em seu poder de propor representações e articulações de significados instantaneamente a uma quantidade enorme e indistinta de pessoas" (GASTALDO, 2002, p. 211). Nesse sentido, a publicidade é compreendida como elemento que naturaliza a articulação entre os significados e opera na "manutenção de uma determinada relação de forças" (p. 224) ao mesmo tempo em que se institui como um campo de lutas (pela "versão dominante", mais "aceita").

Já a pesquisa de André Iribure $^{10}$ (2008) revela o papel da publicidade não só na manutenção mas também na transformação das representações sociais. Voltada para "as representações das homossexualidades na publicidade e propaganda", a investigação aborda o tema a partir de um recorte temporal, apostando numa análise em perspectiva diacrônica para investigar transições discursivas. Tal como Rocha (1990) e Gastaldo (2002), Iribure (2008) caracteriza a publicidade como um determinado "regime de representação [...] regulado pelo que pode ser público e idealizado na cultura hegemônica" (IRIBURE, 2008, p. 11-12).

\footnotetext{
${ }^{9}$ Para essa discussão serão consideradas as contribuições do livro "Pátria, chuteiras e propaganda: o brasileiro na publicidade da Copa do Mundo" que foi fruto de sua tese de doutorado (GASTALDO, 2002).

${ }_{10}$ Para essa discussão serão consideradas as contribuições da tese de doutorado "As representações das homossexualidades na publicidade e propaganda veiculadas na televisão brasileira: um olhar contemporâneo das últimas três décadas" (IRIBURE, 2008).
} 
Ao reunir subsídios da Teoria das Representações Socais de Moscovici na sua ênfase estruturalista - pela teoria do "núcleo central" (ABRIC, 2001) - e o viés de Hall, o estudo demonstra que a complexidade das representações publicitárias está, justamente, nos "significados construídos em tensão, nos espaços de contenção da norma, de negociação e possibilidades de alteração" (IRIBURE, 2008, p. 12). Ou seja, as representações estão sob regulação e, ao mesmo tempo, em “provocação da ordem hegemônica” (p. 139).

Através do método da análise de conteúdo (voltada para a temática buscada), o pesquisador infere o que seria o "[...] valor simbólico, o ideal que o texto constrói e entra em tensão com a presença das minorias sexuais” (IRIBURE, 2008, p. 211). A análise resulta na observação de duas categorias principais de representação das homossexualidades: "Representações Estereotipadas" e "Representações Desconstrucionistas" ", a partir das quais se observam indícios de uma "transição sob tensionamento" (p. 283).

Uma importante contribuição do estudo está em demonstrar que “[...] o papel da publicidade e propaganda nas transformações das representações é fundamental como elemento mediador e balizador da cultura contemporânea no que tange às alterações das representações das homossexualidades alinhada à luta histórica [...]” (IRIBURE, 2008, p. 288).

Assim como os outros dois estudos sobre as representações publicitárias produzidos no contexto brasileiro que elegemos para ilustrar esse debate, esta pesquisa revela a posição tensional da comunicação persuasiva entre a naturalização e a disputa por novas categorias hegemônicas. Essa compreensão da publicidade passa pela articulação dos estudos com a discussão sobre a configuração e circulação de representações na cultura.

\section{CONSIDERAÇÕES}

A consolidação da abordagem da publicidade a partir de suas representações, evidenciada ao longo do artigo, pressupõe o entendimento da comunicação persuasiva como lugar privilegiado de análise da circulação de representações na cultura, especialmente nas suas formas de organização mais hegemônicas.

\footnotetext{
11 A primeira categoria expressa "as fronteiras da normalidade" dentro da lógica da heterossexualidade (IRIBURE, 2008, p. 213). Já a segunda expressa "formas alternativas de vivência da sexualidade" refletindo, de certa forma, "[...] reconfigurações sociais aliadas à luta histórica das minorias sexuais e do movimento homossexual" (p. 240).
} 
Graças à heterogeneidade dos olhares de Moscovici (1978), Goffman (1979) e Hall (2016) que discutimos, podemos nos referir tanto às representações de "categorias de pessoas" e situações cotidianas na realidade "hiperritualizada" na imagem publicitária, quanto às representações enquanto conjunto de saberes, crenças e valores, sistemas classificatórios do mundo ou enquanto processos de significação.

$\mathrm{O}$ resgate de algumas pesquisas realizadas no cenário brasileiro, fundamentadas em variadas perspectivas do estudo das representações, trouxe indicativos de que a publicidade pode ser abordada como sistema mágico-totêmico, mito e rito, na perspectiva da antropologia simbólica (ROCHA, 1990); como mecanismo de naturalização e manutenção das relações de poder, no viés de Goffman e Hall (GASTALDO, 2002); ou como "elemento mediador e balizador da cultura contemporânea", alinhado a grupos sociais e suas disputas, no viés da Teoria das Representações Sociais (IRIBURE, 2008). Nessas investigações, é relevante o olhar diacrônico, que revela pela publicidade o paradoxo entre a novidade anunciada e a semelhança estrutural com que suas representações são narradas ao longo do tempo (ROCHA, 2006).

A ênfase dada ao tema pela produção científica brasileira sobre publicidade se justifica pela ampla contribuição da discussão das representações às investigações da área, à exemplo das pesquisas aqui destacadas. Com base em um traço comum a essas contribuições, podemos afirmar que as representações publicitárias são formuladas ancorando-se em outras representações, vinculadas às diferentes práticas, contextos, e grupos sociais que o processo comunicativo publicitário aproxima. A própria "articulação da publicidade com o mudo social" (PIEDRAS, 2009) incide sobre a construção seletiva e esquematização do núcleo figurativo das representações publicitárias (MOSCOVICI, 1978; JODELET, 2001), pressionam sua organização de forma a mantê-la ou transformá-la (IRIBURE, 2008). A noção de articulação está fundamentada na observação de elementos que "[...] passam a coabitar um discurso [...] ou não em conjunturas específicas”, o que demanda uma estratégia investigativa que observe "a vinculação de seus textos [da publicidade] às forças sociais que os condicionam" (PIEDRAS, 2009, p. 53).

Em diálogo com essa ideia, os estudos aqui destacados demonstram como a publicidade se constitui num “campo de lutas" (GASTALDO, 2002; IRIBURE, 2008), ao mesmo tempo que ritualiza uma realidade reordenada em função do produto (ROCHA, 1990), naturalizando-a e contribuindo para a hegemonia de representações ligadas ao sistema capitalista (COLÓN ZAYAS, 2001). Assim, a abordagem do fenômeno das representações 
complexifica a compreensão da publicidade na trama social ao endereçar reflexões sobre as relações entre representação, comunicação e cultura, para além do sistema comercial (WILLIAMS, 1995).

Sob esse viés, pode-se encarar o papel da comunicação persuasiva nas dinâmicas que contribuem para os processos de partilha e ritualização, manutenção ou transformação de conjuntos de conceitos e imagens articulados às práticas sociais. Através de estudos que discutem a recorrência de certos temas na publicidade, a consolidação de estereótipos ou as práticas de significação nesse processo comunicativo, a apropriação das distintas vertentes de discussão das representações vem situando a pesquisa em publicidade no amplo debate sobre processos interpretativos, relações de poder e construção de identidades, contribuindo de forma crescente para sua relevância no campo da Comunicação.

\section{REFERÊNCIAS}

ABRIC, Jean-Claude. O estudo experimental das representações sociais. In: JODELET, Denise (org.). As Representações Sociais. Rio de Janeiro: EdUERJ, 2001, p. 155-172.

COLÓN ZAYAS, Eliseo. Publicidad y Hegemonía - Matrices Discursivas. Buenos Aires: Grupo Editorial Norma, 2001.

DURKHEIM, E. MAUSS, M. Algumas formas primitivas de classificação. In: RODRIGUES, José Alertino (org.). Émile Durkheim. Editora Ática: São Paulo, 2008[1902] (p. 183-203).

GASTALDO, Édison Luís. Pátria, chuteiras e propaganda: o brasileiro na publicidade da Copa do Mundo. São Paulo: Annablume; São Leopoldo, RS: Ed. Unisinos, 2002.

GOFFMAN, Erving. Gender Advertisements. New York: Harper Torchbooks, 1979.

GOMES, Neusa (coord.), CORRADI, A. CURY, L. A Dialética Conceitual da Publicidade e da Propaganda. In: Publicidade: Análise da Produção Publicitária e da Formação Profissional. São Paulo: Comunicação Publicitária ALAIC, 1998.

HALL, Stuart. Cultura e Representação. Rio de Janeiro: Ed. PUC-RIO; Apicuri, 2016[1997].

. Significação, representação, ideologia: Althusser e os debates pós-estruturalistas. In: Da

Diáspora: Identidades e Mediações Culturais. Belo Horizonte : Editora UFMG, 2003.

Quem precisa de identidade? In: SILVA, Tomaz Tadeu da (org.). Identidade e diferença: a

perspectiva dos Estudos Culturais. 15. ed - Petrópolis, RJ: Vozes, 2014

IRIBURE, André. $\mathbf{B} \quad$ bb

"'Tese de Doutorado apresentada ao Programa de Pós-graduação em Comunicação e informação da UFRGS. Disponível em

<https://www.lume.ufrgs.br/bitstream/handle/10183/13806/000655317.pdf?sequence=1 >. Acesso em 23-12-2015.

,,,,,..,$/ . / / I / / / / / / / / /^{\circ 000}$ 
JACKS, Nilda. A publicidade vista pela academia: tendências dos anos 90. In: RAMOS, Roberto (org.). Mídia, Textos e Contextos. Porto Alegre: PUCRS, 2001, p 205-219.

JODELET, Denise. Representações Sociais: um domínio em expansão. In: JODELET, Denise (org.) As Representações Sociais. Rio de Janeiro: EdUERJ, 2001, p. 17-44.

JOVCHELOVITCH, Sandra. Os contextos do saber: representações, comunidade e cultura. 2. ed. Petrópolis, RJ: Vozes, 2011.

MOSCOVICI, Serge. As Representação Social da Psicanálise. Rio de Janeiro, Zahar, 1978 [1961].

Representações Sociais - investigação em psicologia social. Petrópolis, RJ: Vozes, 2003.

PIEDRAS, Elisa Reinhardt. Fluxo Publicitário - Anúncios, Produtores e Receptores. Porto Alegre: Sulina, 2009.

PROCTER, James. Stuart Hall. Routledge: New York, 2004.

ROCHA, Everardo P. Guimarães. Magia e capitalismo: um estudo antropológico da publicidade. 2. ed. São Paulo: Brasiliense, 1990.

Representações do consumo: estudos sobre a narrativa publicitária. Rio de Janeiro: Ed. PUC-Rio. Mauad, 2006.

STUMPF, Ida Regina C. Pesquisa Bibliográfica. In: DUARTE, Jorge; BARROS, Antonio. Métodos e Técnicas de pesquisa em comunicação. 2. Ed. São Paulo: Atlas, 2008.

WILLIAMS, Raymond. Advertising: the magic system. In: DURING, Simon (org.). The Culture Studies Reader. London: Routledge, 1995 [1961], p.320-336.

Original recebido em: 21 de novembro de 2016

Aceito para publicação em: 22 de agosto de 2017

\section{Nathália dos Santos Silva}

Bacharel em Comunicação Social/Publicidade e Propaganda (2013) e mestre em Comunicação e Informação pela Universidade Federal do Rio Grande do Sul (2016), pesquisou as "Representações sobre 'novas tecnologias' no fluxo publicitário televisivo" e foi bolsista da Capes. Interessa-se pela abordagem sociocultural da publicidade e por temas como representações e relações entre tecnologia e sociedade.

\section{Elisa Reinhardt Piedras}

Bacharel em Comunicação Social/Publicidade Propaganda pela Universidade Católica de Pelotas (2002) e em Artes Visuais/Design Gráfico pela Universidade Federal de Pelotas (2003). Mestre em

Comunicação e Informação na Universidade Federal do Rio Grande do Sul (2005), Doutora em

Comunicação pela Pontifícia Universidade Católica do Rio Grande do Sul (2007) com Estágio de Doutorado no Exterior na Universidade Paris V - Sorbonne (2007), com bolsa da Capes. Professora da Universidade Federal do Rio Grande do Sul, atuando no Departamento de Comunicação e na Linha de 
Pesquisa "Cultura e Significação" do Programa de Pós-Graduação em Comunicação. Pesquisa temas como o processo de comunicação publicitária e sua abordagem sociocultural, estudos de recepção, consumo cultural, consumo e consumidor. Coordena o Projeto de Pesquisa "Especificidades da recepção da publicidade: como são feitos e o que dizem os estudos brasileiros recentes sobre a relação do público com esse gênero". É autora do livro "Fluxo publicitário" e de diversos artigos sobre publicidade e recepção midiática publicados em periódicos nacionais.

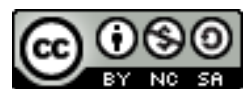

Esta obra está licenciado com uma Licença

Creative Commons Atribuição-NãoComercial-CompartilhaIgual 4.0 Internacional 